\title{
DA ANÁLISE ÀS INTENÇÕES DO PROJETO: CONCEITOS PARA O PROCESSO DE CONCEPÇÃO DA PAISAGEM
}

\author{
FROM ANALYSIS TO DESIGN: CONCEPTS FOR LANDSCAPE CONCEPTION
}

\section{FEGHALI, Maria Elisa}

Arquiteta, Ms. em arquitetura, Programa de Pós-Graduação em Arquitetura (Proarq), Universidade Federal do Rio de Janeiro (UFRJ), especialista em Planejamento Ambiental e Paisagístico pela SNA, Rio de Janeiro.

E-mail:memf@domain.com.br

\section{LASSANCE, Guilherme}

Arquiteto, doutor em arquitetura pela Universidade de Nantes, França. Professor da Faculdade de Arquitetura e Urbanismo da Universidade Federal do Rio de Janeiro (FAU-UFRJ)

E-mail: lassance@ufri.br

\section{RESUMO}

O artigo que apresentamos aqui faz parte de uma reflexão acerca dos espaços livres públicos, reconhecendo sua característica mutante. Respaldados por algumas experiências pedagógicas, notamos uma dificuldade recorrente por parte dos projetistas, em transpor os elementos advindos da etapa de análise dos contextos a serem trabalhados, para a etapa de projeto. Sendo assim demonstraremos como alguns conceitos que chamamos de identificadores de componentes da paisagem e indicadores de qualidades da paisagem, se revelam como importantes ferramentas de auxílio para a transposição da análise ao projeto. Estes conceitos possibilitam a integração, de diferentes dimensões do espaço: morfológica, comportamental e sensorial, permitindo ao projetista uma análise não só interpretativa mas também valorativa dos contextos de intervenção.

Palavras-chave: Processo de concepção, paisagem, ensino.

\begin{abstract}
This paper is the result of a reflexion about public free spaces, regarded as spaces to be thought of and conceived by a project. As we recognize in public free spaces the characteristics of an ever changing entity and based on some pedagogical experiences, we have noticed that students have some recurrent dificulty to overcome obstacles which first appear during the working context analysis prior to the project phase. Therefore, we shall demonstrate how certain concepts which we shall call identifiers of the landscape and landscape quality indicators reveal themselves as important tools to help us to migrate from the analysis phase to the project synthesis. These concepts allow to integrate different space analysis dimensions: morfological, behavioural and sensorial, which are relevant to the aprehension of free public spaces conceived in essence as mutant spaces, and allowing the designer to conduct an interpretative analysis and also to value the intervention contexts.
\end{abstract}

Key words: Design process, landscape, education.

\section{Introdução geral}

Há muito tempo, os espaços livres públicos, principalmente nas grandes cidades, têm um importante papel a desempenhar, como opção para o lazer, interação social, contemplação, descanso, entre outros. Assim, diversos autores concordam que os espaços livres públicos são indispensáveis para o estudo da paisagem urbana e a qualificação do meio urbano, enfatizando, entretanto, diferentes pontos de vista. Alguns discutem a morfologia urbana, dando maior enfoque à questão da forma dos edifícios circundantes e ao impacto formal de sua inserção no tecido urbano 
(ROSSI, 1995; LAMAS, 2000), outros destacam aspectos comportamentais buscando nos indivíduos e nas atividades desenvolvidas por eles nesses espaços, as razões para o incentivo e para a reflexão das áreas livres públicas, (WHYTE, 1980; CARR et al, 1992), outros ainda estudam aspectos relativos a intersensorialidade do espaço urbano e à importância do mapeamento olfativo, sonoro, sensitivo térmico e tátil - como conformadores de uma paisagem sensorial, determinante do uso e da forma desses espaços (AUGOYARD, 1998; THIBAUD, 1998)'.

Neste sentido, entendemos que, os métodos que permeiam os projetos para estes espaços, devam considerar entre outros aspectos sua característica essencialmente mutante, como espaços que se transformam continuamente, quer seja por sua ambiência ou pela ação de seus usuários. Notamos, como consequência disso, uma dificuldade recorrente por parte dos alunos, em transpor os elementos advindos da etapa de análise dos contextos a serem trabalhados, para a etapa de projeto ${ }^{2}$. Entendemos que parte dessa dificuldade é inerente à própria condição dos alunos, que como projetistas ainda em formação, não dominam o manejo das possíveis pistas de projeto, reveladas na etapa de análise. Por outro lado, acreditamos que essa dificuldade refere-se, também, à falta de métodos e ferramentas que permitam orientar os alunos na etapa de transposição análise/projeto.

Sendo assim demonstraremos que alguns conceitos se revelam como importantes ferramentas de auxílio para a transposição da etapa de análise para a de projeto. Estes conceitos possibilitam a integração de diferentes dimensões de análise do espaço: morfológica, comportamental e sensorial, relevantes para a apreensão dos espaços livres públicos permitindo uma análise não só interpretativa mas também valorativa dos contextos de intervenção.

Os identificadores tiveram como base o suporte conceitual desenvolvido por Gordon Cullen em Paisagem urbana (1971) e os indicadores se apoiaram nos conceitos desenvolvidos por Steemers (1995), Dupagne (1999) e Lassance (2000) para estudos de diferentes meios de representação da forma dinâmica.

Apontamos também para a importância da subjetividade da categorização do mundo real, evidenciada por Eleanor Rosch (1976), e expressa na hierarquização dos elementos definidos pelas ferramentas conceituais refletindo a importância das "balizas cognitivas".

\section{1 - Ferramentas conceituais}

Projetar reflete uma intenção de se atender a um ou a múltiplos objetivos e/ou exigências; deste modo, o entendimento de que existe uma relação direta e necessária entre análise e projeto e que o caminhar progressivo (da análise para o projeto), assim como em um jogo de xadrez, deverá ser construído pelo manejo das peças conceituais, aliadas às estratégias e referências, permitindo a construção de um projeto mais afinado com a realidade vivencial do espaço.

Neste sentido algumas ferramentas conceituais podem ser utilizadas como contribuição para a análise do espaço tanto no sentido descritivo como valorativo auxiliando a construção da "ponte" análise/projeto. A construção de tais ferramentas conceituais apóia-se na intenção principal de reduzir o caráter muitas vêzes arbitrário do processo de concepção dos espaços livres públicos, mostrando que existe uma relação entre análise e projeto, e que qualquer que sejam os objetivos que se pretenda atingir no processo de concepção, eles dependerão do entendimento de como o espaço se apresenta para o projetista e das tensões existentes entre todas as características que lidam com outras dimensões da forma, que não somente a visual.

É fundamental reconhecer que todo diagnóstico constitui uma operação interpretativa e como tal estabelece uma versão, da realidade observada, que por si só já configura as condições do projeto. Que as referências projetuais consolidem e articulem o cenário de dados contextuais ou ainda iluminem componentes e qualidades do espaço que não haviam sido considerados 
pelo diagnóstico inicial, sua convocação no processo de concepção não pode contentar-se da mera influência de tendências da moda mas deve, ao contrário, estabelecer uma relação clara com a análise do contexto de intervenção.

De fato, em estudos precedentes elaborados há quase dez anos e fundamentados em trabalhos de outros pesquisadores como os da corrente de pesquisas de cunho epistemológico encabeçada por Philippe Boudon na França, desde o início dos anos de 1970, como também em teses da vertente metodológica de procedência anglo-saxã - os chamados design methods - pôde-se verificar que a construção dessa relação entre análise e projeto depende principalmente da disponibilidade de conceitos comuns a essas duas fases do processo de concepção. Daí a hipótese, alicerce da presente pesquisa, que sustenta a necessidade de se dispor de categorias de análise que correspondam às de projeto.

\section{2 - Problemas da categorização}

Classificar os objetos do mundo real, dentro de algumas categorias conceituais, nos revela um embate entre as definições conceituais propostas e a identificação dos elementos da paisagem que expressem tais conceitos. $O$ caráter ambíguo de algumas definições suscita uma série de dúvidas quanto à identificação de alguns conceitos. Percebemos, por exemplo, que alguns elementos identificados podem pertencer a mais de uma categoria conceitual.

Recorrendo aos conceitos de G. Cullen (1971), examinemos, por exemplo, o caso do prédio da Cândido Mendes, no centro da cidade do Rio de Janeiro: quando visto da praça XV, pode ser identificado como um acidente, se considerarmos que ele destoa de seu entorno construído; mas por outro lado se o considerarmos como um ponto de convergência de pessoas, considerando sua função, então o classificaremos como ponto de atração. Notemos que estas categorias dependem, ainda, do contexto em que o observador se encontra: o mesmo prédio da Cândido Mendes, se observado de quem está em Niterói, não se qualificará como acidente, pois daquele ponto de vista ele não destoará de seu entorno; pelo contrário se confundirá com toda densidade construída do centro da cidade (Figura 1).



Figura 1: Edifício da Cândido Mendes, visto a partir da praça XV, Rio deJaneiro (esquerda) e o mesmo ediff́cio visto da baía de Guanabara, inserido no conjunto de prédios do centro da cidade

Fonte : FEGHALI, 2005

Essa confrontação do acervo de conceitos definidos por Gordon Cullen, com a realidade construída, nos conduz a uma investigação sobre a natureza do processo de categorização de objetos e estímulos do mundo real.

Na década de 1970, Eleanor Rosch discute os princípios universais de categorização dos estímulos perceptivos concretos do mundo. A autora defende a proposição de que os objetos concretos são classificados em categorias de forma não completamente arbitrária. $\bigcirc$ que se pretende universal, na pesquisa de Rosch, são os princípios de formação das categorias. 
A autora sustenta que os atributos do mundo real, contrariamente aos conjuntos apresentados em laboratório, não se apresentam independentemente uns dos outros. Portanto, no mundo real, as categorizações, mesmo que naturais, não são ideais, fechadas, pois existem relações variadas entre objetos de diferentes categorias, que às vezes diluem fronteiras e às vezes criam pontes entre categorias. A autora propõe ainda que a melhor representação das categorias seria através de elementos protótipos, característicos dessas categorias.

Quer dizer que, como numerosas experiências mostram, as categorias não são codificadas no espírito nem por meio de listas de todos os membros individuais da categoria, nem por meio de uma lista de critérios formais necessários e suficientes para definir o pertencimento a esta categoria, mas, acima de tudo, sob a forma de um protótipo ou uma imagem concreta de um membro médio desta categoria (ROSCH, 1976, p. 245).

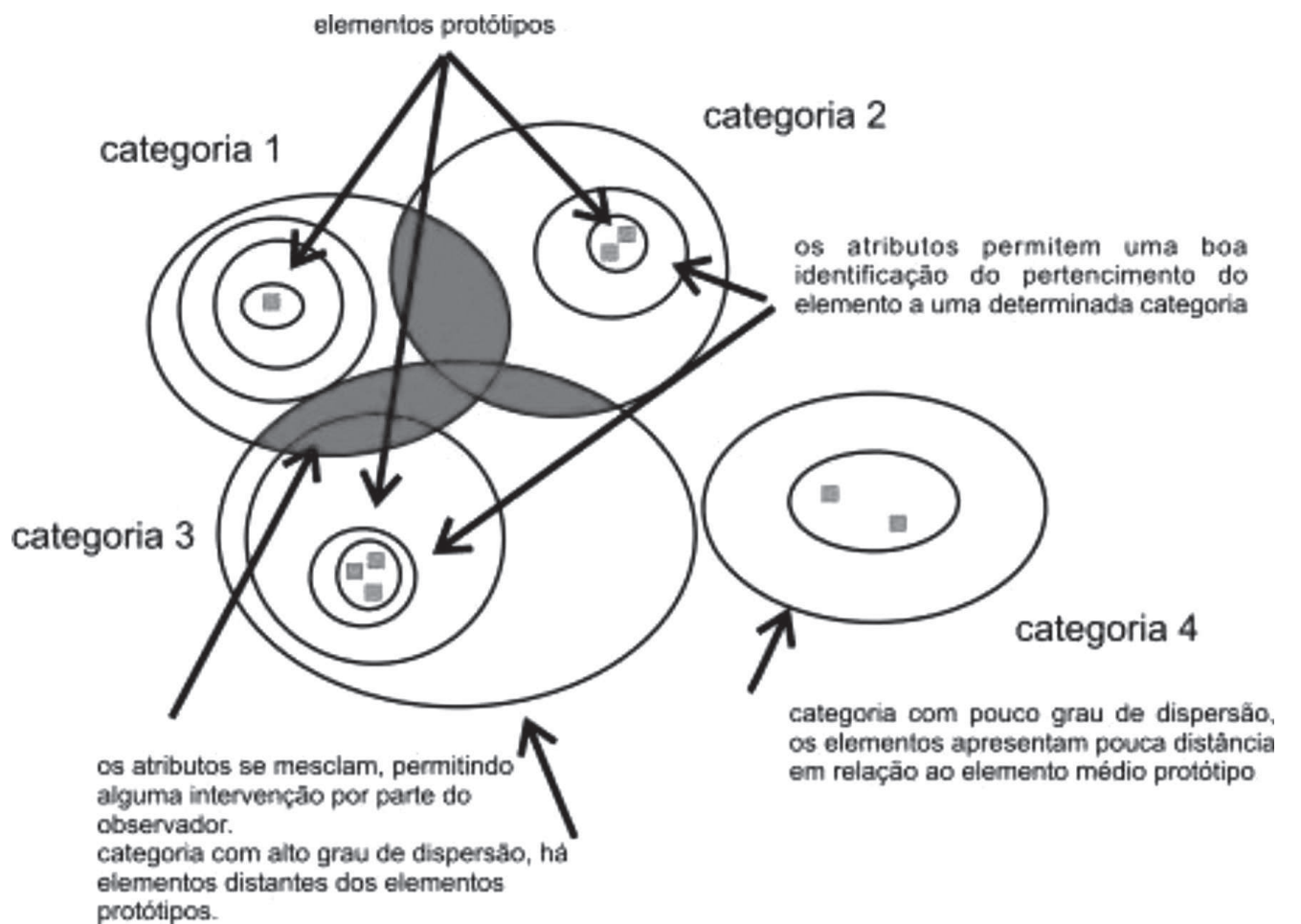

Gráfico de categorização de objetos de base Fonte: FEGHALI, 2005

A autora define as categorias dos objetos de base como as categorias mais globais que têm um número grande de atributos em comum, cujos objetos da categoria sejam também semelhantes em sua aparência visual. Os mesmos princípios determinam quais membros serão percebidos como os mais típicos protótipos, ou representantes dessa categoria: serão, portanto, aqueles com o maior número de atributos comuns com o maior número de membros da categoria. Sendo assim, igualmente, os itens mais típicos da categoria dentro de uma visão de conjunto.

\section{3 - O repertório de conceitos}

Os conceitos identificadores de componentes da paisagem (ICP) - cujo termo foi usado por designar a possibilidade de reconhecimento dos componentes da paisagem com uma determinada categoria de entidades paisagísticas, dentro de uma lógica binária (existe/não existe) - são conceitos que nos permitem identificar os atributos que são próprios do espaço (conceitos definidos por G. Cullen). No caso dos indicadores de qualidades da paisagem (IQP), contrariamente aos identificadores, são conceitos que apontam características variáveis $(+/)$ dentro de um gradiente de intensidade ou magnitude. 
A relevância dos conceitos indicadores de qualidades da paisagem para a articulação da análise ao projeto, se deve ao fenômeno de hierarquização que permeia todo projeto: esses conceitos (indicadores) possibilitam a valoração dos aspectos de uma situação analisada no sentido de construção de um problema de projeto (coluna esquerda da Tabela 1 apresentada abaixo).

\begin{tabular}{|l|l|}
\hline $\begin{array}{l}\text { Continuidade: sugere a atribuição de uma iden- } \\
\text { tidade (persistência de limite/superfície) }\end{array}$ & Acidente, barreira, sub-espaço, trajetória \\
\hline $\begin{array}{l}\text { Diversidade: indica a presença de unidades } \\
\text { paisagísticas e de contrastes entre elas }\end{array}$ & $\begin{array}{l}\text { Acidente, barreira, sub-espaço, elemento } \\
\text { efêmero, pormenor }\end{array}$ \\
\hline $\begin{array}{l}\text { Exposição: grau de influência de fenômenos } \\
\text { externos ao espaço considerado }\end{array}$ & $\begin{array}{l}\text { Acidente, além, barreira, componente efêmero, } \\
\text { indício, sub-espaço, trajetória }\end{array}$ \\
\hline $\begin{array}{l}\text { Informalidade: permite avaliar o grau de cor- } \\
\text { respondência entre o uso e o desenho do espaço }\end{array}$ & $\begin{array}{l}\text { Barreira, componente efêmero, sub-espaço, } \\
\text { indício }\end{array}$ \\
\hline $\begin{array}{l}\text { Mutabilidade: introduz a dimensão temporal na } \\
\text { relação entre o espaço e seu uso }\end{array}$ & $\begin{array}{l}\text { Barreira, componente efêmero, sub-espaço, } \\
\text { indício }\end{array}$ \\
\hline $\begin{array}{l}\text { Permeabilidade: depende do numero de alterna- } \\
\text { tivas de deslocamento através de um meio }\end{array}$ & Além, barreira, componente efêmero, trajetória \\
\hline $\begin{array}{l}\text { Saturação: multiplicação de dados e sinais sen- } \\
\text { soriais, podendo ser local ou global }\end{array}$ & $\begin{array}{l}\text { Acidente, barreira, componente efêmero, ponto } \\
\text { de atração, pormenor, sub-espaço }\end{array}$ \\
\hline $\begin{array}{l}\text { Significação: mede a intensidade simbólica dos } \\
\text { diferentes componentes paisagísticos }\end{array}$ & $\begin{array}{l}\text { Acidente, barreira, indício, ponto de atração, } \\
\text { pormenor, trajetória }\end{array}$ \\
\hline $\begin{array}{l}\text { Singularidade: qualidade do que é único e } \\
\text { diferente }\end{array}$ & $\begin{array}{l}\text { Acidente, barreira, componente efêmero, ponto } \\
\text { de atração, pormenor, sub-espaço, trajetória }\end{array}$ \\
\hline $\begin{array}{l}\text { Viscosidade: resistência ao movimento, graus de } \\
\text { aderência ao espaço }\end{array}$ & $\begin{array}{l}\text { Acidente, barreira, componente efêmero, sub-espaço, } \\
\text { trajetória (redutor) }\end{array}$ \\
\hline
\end{tabular}

Tabela 1: Relação dos conceitos indicadores de qualidades da paisagem com os conceitos identificadores de componentes paisagísticos

Sublinhamos também, nesta tabela, que a análise da relação dos identificadores de componentes paisagísticos com os indicadores de qualidades da paisagem, tem como objetivo não somente introduzir a definição da cada indicador, como também relacioná-lo com os componentes paisagísticos que interferem com o estado de cada qualidade descrita.

Constatamos, assim, que a caracterização dos indicadores, embora proveniente de uma análise objetivante, envolverá uma interpretação subjetiva por parte do projetista/observador e que a forma na qual se dá essa interpretação é fundamental porque ela estará presente no direcionamento de uma parte do projeto.

Retomando aqui algumas das observações feitas em trabalhos precedentes (LASSANCE, 2003), podemos considerar que a organização intencional que o projetista opera sobre seu imaginário e que é decorrente deste momento de interpretação do contexto é parcialmente determinada por suas orientações ideológicas e doutrinárias mas também pelos métodos gerados por sua prática (experiência pessoal). $\bigcirc$ projetista aborda assim a análise da situação através de soluções conjeturais cuja avaliação do grau de pertinência diante dos dados do contexto the permite "descobrir" as propriedades que a solução final deverá possuir. Essas propriedades que o enunciado do problema deverá integrar não são diretamente legíveis na situação. Elas resultam de um processo de "tradução", em termos que interessam cada projetista, dos dados multiformes e conflitantes de cada situação. 
A dificuldade de visualização de alguns desses conceitos, já que eles não pertencem a categorias estanques morfológicas, implica que cada projetista lhes confira o relevo e a interpretação que considerar pertinente; nesse caso, estes conceitos serão balizas-referência das quais os poderse-á ou não se aproximar .

\section{4 - A aplicação dos conceitos e o problema da representação}

Para que o mapeamento, dos conceitos identificadores de componentes paisagísticos, fosse possível, foi necessário a criação de uma legenda gráfica, que permitisse a representação do repertório conceitual em planta e com isso sua real integração ao processo de concepção paisagística (Tabela 3).

Tabela 2: Representação dos conceitos identificadores de elementos paisagísticos

Fonte: FEGHALI, 2005

\begin{tabular}{|c|c|c|c|c|c|}
\hline Acidente & & Componente efêmero & 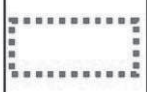 & Pormenor & $\begin{array}{l}a \\
b \\
c\end{array}$ \\
\hline Além & $\langle\cdots \cdots \cdot\rangle$ & Indício & 米 & Sub-espaço & \\
\hline Barreira & सس & Ponto de atração & $\underset{\rightarrow i K}{\searrow K}$ & Trajetória & \\
\hline
\end{tabular}

Lembremos também que cada um desses conceitos tem a capacidade de agregar outras qualidades que não as visuais, e nestes casos os alunos, alvos de nossa experiência, deveriam utilizar uma legenda adicional: A para elementos visuais, B para os auditivos, e C para a relação olfativa ${ }^{4}$.

É ainda importante considerar que os conceitos não são categorias estanques, fazendo com que um elemento possa ser mapeado em diferentes categorias ${ }^{5}$.

\section{5 - Mapa-síntese}

Os elementos a serem selecionados, na chamada etapa de análise, deveriam, em seguida, ser enquadrados dentro das categorias conceituais definidas pelos identificadores de componentes paisagísticos, segundo uma análise subjetiva do projetista apresentada através de um mapa síntese com a seleção do repertório conceitual que para ele se apresentou como mais significativo de ser transposto para a etapa de projeto.

A confecção do mapa síntese da análise obedeceu a um procedimento metodológico composto por quatro etapas (Figuras 2 e 3):

1a etapa: levantamento em campo

Os alunos, de posse das plantas baixas, com a definição dos territórios existentes em cada praça, foram a campo, com objetivo de fazer um levantamento global dos Identificadores de Componentes da Paisagem (ICP), registrando-os graficamente em planta, segundo legenda pré-definida 6 .

2a etapa: hierarquização dos identificadores

Os alunos procederam a uma valoração dos elementos identificadores, segundo critérios analíticos e interpretativos; esta etapa já implicou em escolhas, tanto dos elementos que serão transpostos para o projeto, quanto de sua escala de importância. 
3a etapa: execução do mapa-síntese

Representação em planta dos elementos selecionados na etapa anterior (utilização da escala gráfica da Tabela 2)

4a etapa: feedback

Retorno a campo para constatar e aferir o mapa-síntese, que estará sujeito a correções e modificações:

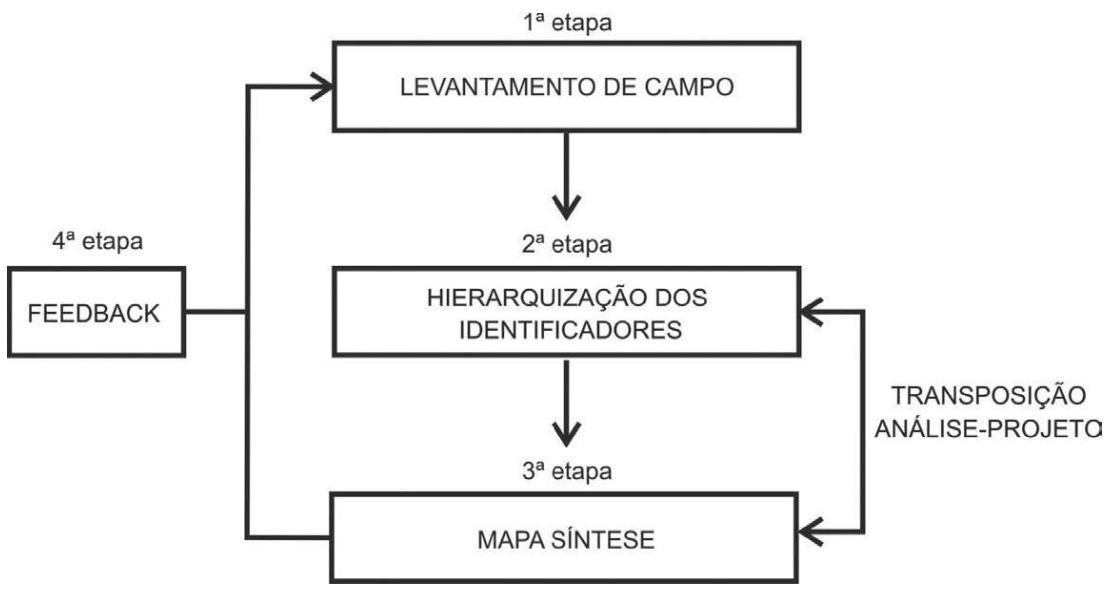

Esquema - Gráfico da confecção do mapa-síntese Fonte: FEGHALI, 2005

Ilustraremos a seguir a confecção de mapas síntese da análise, desenvolvidos por dois grupos distintos de alunos, para a disciplina de paisagismo II da FAU/UFRJ, para as praças Mauá e Melvin Jones respectivamente (Figuras 2 e 3).

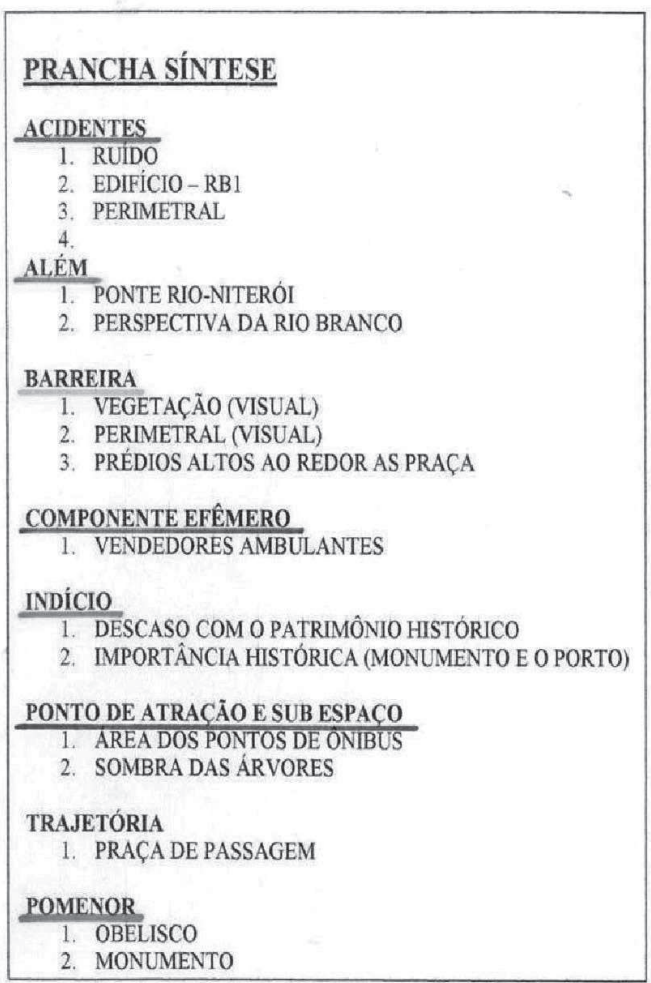

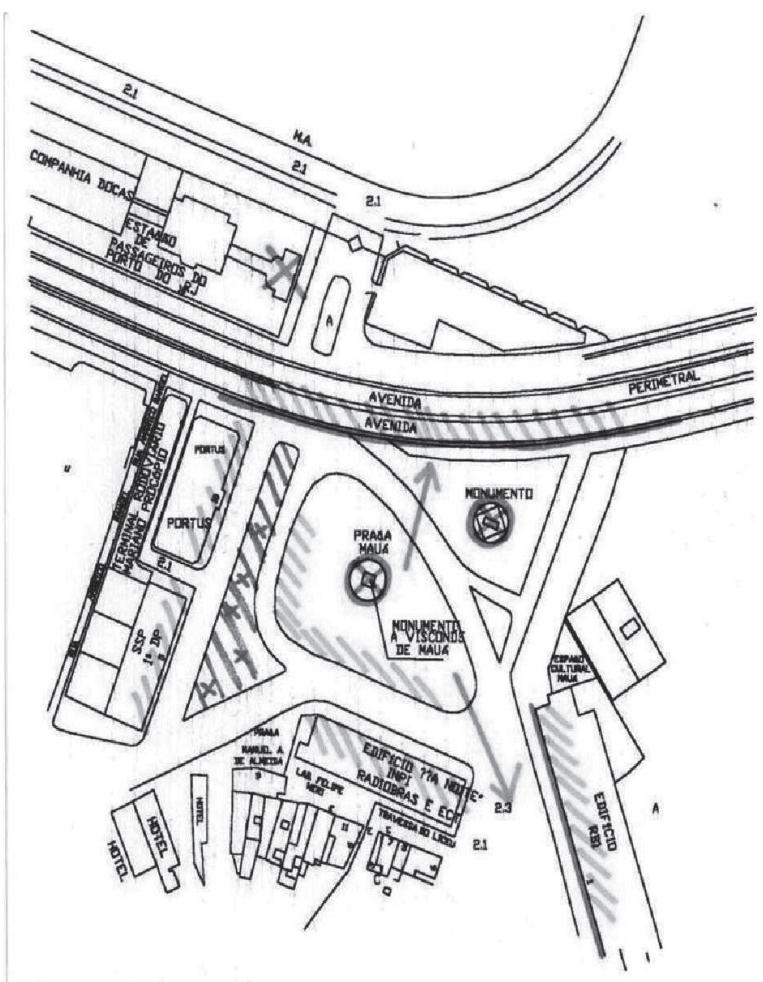

Figura 2: Mapa-síntese da análise, praça Mauá, RJ

Fonte: Os alunos Giovani Serpa, Caroline Reis e Juliana Peixoto 


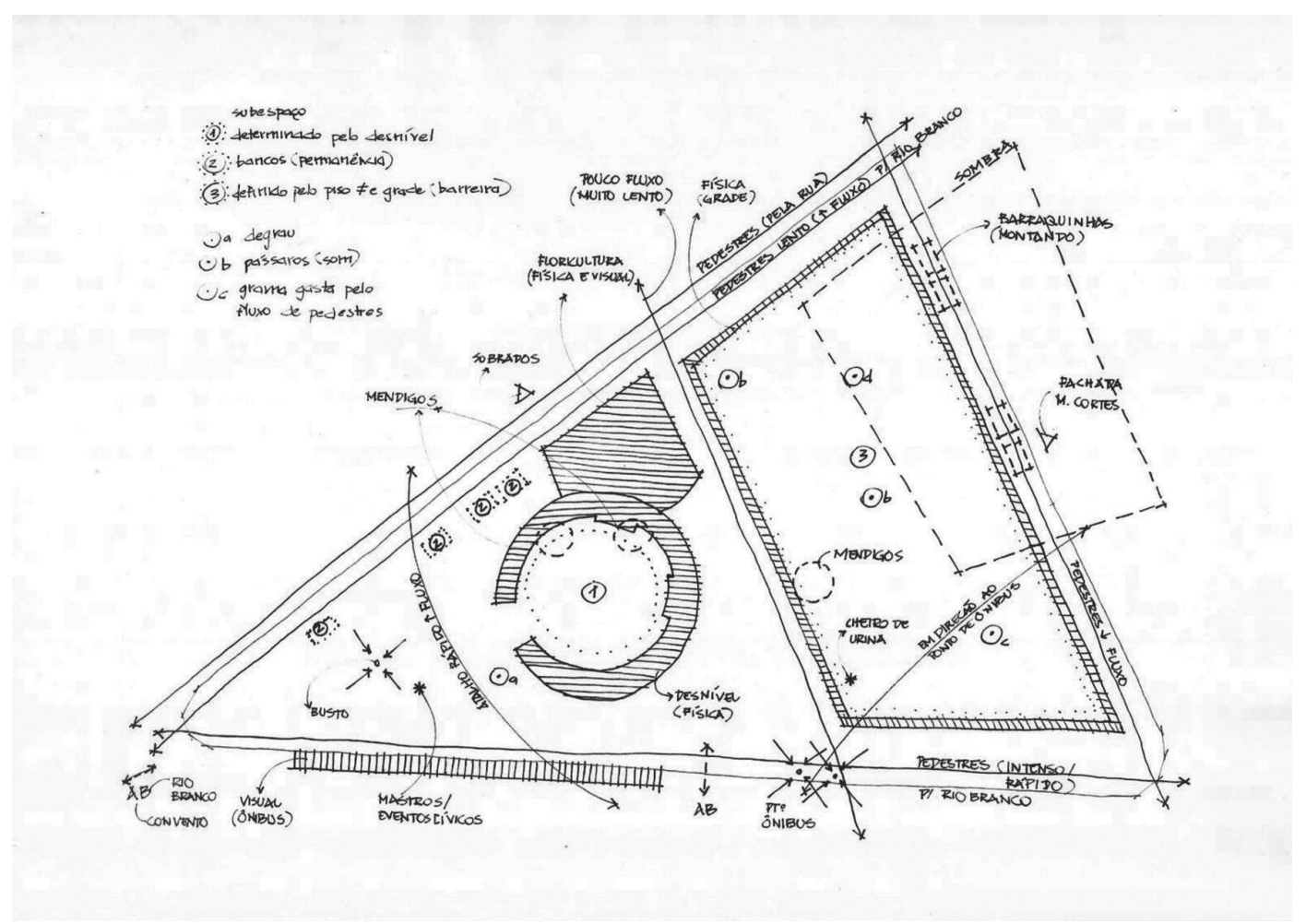

Figura 3: Mapa-síntese da análise, praça Melvin Jones, RJ

Fonte: As alunas Paula Costa e Fernanda Guimarães

Barreiras - Grade que divide a praça em duas, degraus do teatro de arena, floricultura.

Trajetórias - Principal pela rua Nilo Peçanha, mais lenta, pela rua Graça Aranha, determinada em parte pela textura do paralelepípedo; outra bem mais lenta, pela rua da Quitanda; uma transversal ao anfiteatro existente, uma pelo gramado, ligando o prédio do Menezes Cortes ao ponto de ônibus da rua Nilo Peçanha.

Ponto de atração - O ponto de ônibus da rua Nilo Peçanha, e o busto onde acontecem atividades cívicas.

Além - A vista do convento de Santo Antônio.

Subespaço - Área determinada pelo desnível, área gramada, bancos embaixo das árvores, conjugados às sombras.

Elemento efêmero - A sombra do edifício Menezes Cortes, ela é tão importante, que é quase um elemento permanente; as barracas dos ambulantes, e os mendigos.

Acidente - $O$ prédio do Menezes Cortes, por ser destoante e impactar com o seu entorno; e os sobrados na rua São José.

Indícios - Mastro para bandeiras, que é usado para eventos cívicos, cheiro de urina.

Pormenor - $\bigcirc$ piar de pássaros no centro da área gramada.

Na etapa subseqüente, o arquiteto procurará os "personagens" ou usuários potenciais da área a ser estudada que por sua vez atuarão como reagentes ao contexto. Do binômio mapa síntese / usuários se definirão textualmente as diretrizes de projeto, com base nas qualidades espaciais que se pretende (indicadores de qualidades da paisagem - IQP) e que serão atendidas pelo manejo dos conceitos que compõem a grade de identificadores de componentes da paisagem.

Exemplo de diretrizes de projeto definidas pelo grupo de alunos com base no mapa-síntese da análise da Figura 2:

"O objetivo do projeto é buscar a diversidade do espaço através de diferentes tipos de piso (vegetação, madeira, intertravado), adequando assim cada espaço a seu uso. Procuraremos resgatar a permeabilidade tanto visual como física ao mar, com a eliminação de algumas barreiras tais 
como a vegetação existente no centro da praça e o guarda-corpo do viaduto da perimetral, que trabalhado como um mural será um atrativo visual. O conceito significação será trabalhado, mantendo o monumento do Barão de Mauá, como resgate da história do local e de sua identidade. Trabalharemos a viscosidade com a construção de um deck e de sub-espaços de permanência nas laterais do acesso que leva ao mar, gerando assim espaços diferenciados."

De posse das diretrizes, e ainda respaldados pela grade de conceitos - identificadores e indicadores, os projetistas buscaram referências que permitiram então balizar a esquematização da proposta e posteriormente o seu desenvolvimento agregando as exigências relativas às normas técnicas e à seleção do material a ser especificado. Sendo assim, as referências, selecionadas pelos alunos, procuravam salientar elementos compatíveis com as qualidades almejadas na intenção de projeto: os conceitos IQP-indicadores de qualidades da paisagem.

Segundo M. Conan (1995), do confronto das referências com os elementos do contexto, o arquiteto cria um ponto de vista inicial que permite abordar a complexidade do real específica de cada situação graças à sua estruturação. "Esse ponto de vista inicial constitui na realidade uma espécie de 'condicionante' que o projetista impõe a si mesmo e que the fornece um alicerce conceitual capaz de gerar soluções originais." (LASSANCE, 2003)

\section{Conclusão}

Para não limitar as decisões projetuais nem a uma análise puramente descritiva de um contexto, nem a um "relâmpago intuitivo", balizado por referências da moda e gosto do próprio projetista, sobretudo os estudantes ainda em formação, expusemos uma grade de conceitos que possibilita aos alunos perceber, analisar o espaço, interpretando-o e concebendo-o com base nestas análises.

Estes conceitos que incorporam tanto as dimensões físicas, quanto comportamental e sensorial, inerentes ao espaço livre, sublinham a importância de uma análise que permita agregar as referências projetuais baseadas nas qualidades almejadas para o espaço e definidas pela análise do contexto dominante e não somente pela genialidade criativa de cada projetista.

O caminhar progressivo do fazer projetual, encontra nas ferramentas conceituais, aqui apresentadas, um suporte para o projetista, sobretudo aqueles ainda em fase de formação, contribuindo para evitar projetos determinados por "fenômenos" da moda, e sem a relação complementar, e necessária, no processo de concepção, entre um contexto dominante e um contexto emergente advindo de uma análise critica e fundamentada.

\section{Notas}

(1) Sobre as dimensões morfológicas dos espaços livres públicos, conferir FEGHALI; LASSANCE, 2004.

(2) Esta pesquisa foi desenvolvida para uma dissertação de mestrado do Programa de Pós-graduação em Arquitetura da FAU-UFRJ - PROARQ, tendo como suporte a aplicação de uma metodologia de projeto, com base nas ferramentas conceituais aqui apresentadas, junto a uma turma da disciplina obrigatória de Paisagismo II oferecida pelo Departamento de Urbanismo e Meio Ambiente (DPUR) da FAU-UFRJ, no segundo semestre de 2004. Duas áreas de intervenção - componentes importantes do sistema de espaços livres públicos do centro da cidade do Rio de Janeiro - foram alvos da disciplina: as praças Mauá e Melvin Jones.

(3) A relevância das balisas conceituais para o estabelecimento de um processo "consciente" de projeto demonstrase justamente através da pluralidade de posicionamentos e estratégias de intervenção obtidas com a experiência de ensino que deu suporte a essa pesquisa. Elas permitem evitar tanto a intuição genial quanto as receitas de soluções pré-concebidas.

(4) Para a legenda do conceito pormenor, estas representações serão utilizadas em letras minúscula, em uma referência ao próprio significado da palavra: pormenor - circunstância particular, minudência, minúcia, miudeza (Conf. HOUAISS, Antônio. Dicionário Hovaiss. Rio de Janeiro. Editora Objetiva, 2003, p. 522). 
(5) É importante aqui novamente salientar que o repertório proposto de conceitos não obriga o projetista a adotar determinadas soluções mas apenas pretende oferecer categorias referenciais capazes de auxiliá-lo na construção de suas próprias intenções projetuais.

(6) Os territórios, para nossa metodologia, são grandes zonas de importância dentro dos espaços das praças: importâncias relativas ao uso, ao comportamento ou à atmosfera sensível. Os registros devem ser feitos com os alunos posicionados no centro de cada território.

\section{Bibliografia}

AUGOYARD, Jean François. Comment observer une ambiance? (Ambiances architeturales et urbaines). Cahier de la recherché arquitecturale. Marseille: Edition Parenthesès, n. 42-43, p. 77-89, 1998.

BOUDON, Philippe. Sur I' espace architectural. Paris: Dunod, 1971.

CARR, S.; FRANCIS, M.; RIVLIN, L.; STONE, A. Public space. Cambridge: Cambridge University Press, 1992.

CONAN, Michel. Les jeux imbriqués de la conception architecturale. In: PROST, R. (Ed.). Concevoir, créer, inventer: Réflexions sur les pratiques. Paris: L'Harmattan, p. 153-188, s/d. (Coll. Villes et entreprises).

CULLEN, Gordon. Paisagem urbana. Lisboa: Edições 70, 1971.

DUPAGNE, Albert; TELLER, Jacques. Restructuration de la place ST. Lambert. Liège: LEMA-Ulg, 1999.

FEGHALI, Maria Elisa. Morfologia ambiental: Uma perspectiva para o projeto de paisagismo. 2005. Dissertação (Mestrado) - PROARQ, UFRJ, Rio de Janeiro, 2005.

FEGHALI, Maria Elisa; LASSANCE, Guilherme. Morfologia ambiental: Uma perspectiva para o ensino do projeto de paisagismo. In: VII ENEPEA, 2004, Belo Horizonte. Anais... Belo Horizonte: ENEPEA, 2004.

HOUAISS, Antônio. Dicionário Houaiss. Rio de Janeiro: Objetiva, 2003.

LAMAS, José. Morfologia urbana e desenho da cidade. Fundação Calouste Gulbenkian, 1989.

LASSANCE, Guilherme. Vingt concepts urbains pour penser l'espace virtuel. In SÉMINAIRE PERCEPTION, INFORMATION, CONCEPTION (FINC), 2000, Toulouse. Anais... Toulouse: EAT, 2000.

Ensinando a problematizar o projeto ou como lidar com a caixa preta da concepção arquitetônica In: PROJETAR 2003 - 1 SEMINÁRIO NACIONAL SOBRE ENSINO E PESQUISA EM PROJETO DE ARQUITETURA, 2003, Natal. Anais... Natal, 2003.

ROSCH, Eleanor. Classifications d'objets du monde réel: Origines et représentations dans la cognition In: Bulletin de psychologie, 1976, n. espécial.

ROSSI, Aldo. A arquitetura da cidade. São Paulo: Martins Fontes, 2001.

STEEMERS et al. Towards Zero Emission Urban Development. Cambridge (UK): The Martin Centre for Architectural and Urban Studies/University of Cambridge, 1995.

THIBAUD, Jean Paul. L'espace urbain en methodes. Marseille: Edition Parenthesès, 2001.

WHYTE, William H. The social life of small urban spaces. Washington, DC: The Conservation Foundation, 1980. 